\title{
DESDE LA DIFERENCIACIÓN A LA INTEGRACIÓN: LA POSIBILIDAD DE AMAR ${ }^{1}$
}

\section{F. Javier Bolívar Jiménez ${ }^{2}$ IPR, Madrid}

Buenos días/tardes.

Sras y Sres, queridos compañeros:

Estamos aquí para habla del amor en lo que concierne al s. XXI.

El amor desde enfoques complementarios no es un asunto fácil.

Tanto en la experiencia clínica de más de 40 años, como en el campo docente, vengo observando el aumento de la negación de la diferencia hombre-mujer.

Las nuevas generaciones tienden progresivamente a negar la diferencia de sexos, y a considerarla una visión del pasado, tal como actualmente defienden.

Es cierto que la relación hombre-mujer no es, exactamente, una relación masculinofemenino. Tampoco se trata de relaciones entre iguales.

Tenemos que hablar de funciones, la función receptiva y la función generativa, ya que se trata de algo que va más allá de la biología, por lo tanto esto ocurre tanto en un sexo como en otro, aunque esto no excluye las diferencias que existen entre un hombre y una mujer.

Antes de continuar considero debemos sabe de dónde partimos.

Mircea Elíade en su libro "Mefistófeles y el Andrógino" (1962) toma el mito de un personaje de Balzac.

Para Elíade es la última gran creación de la literatura europea con el mito del andrógino como concepto fundamental.

Muchos siglos antes encontramos en la mitología oriental y en la cultura mediterránea la androgínia de los dioses desde el punto de vista simbólico.

\footnotetext{
${ }^{1}$ Texto de la intervención de F. Javier Bolivar Jiménez en el Congreso del World Council of Psychotherapy, celebrado en París (2017)

${ }^{2}$ Bolivar Jiménez, F.J. (2018). Desde la diferenciación a la integración: la posibilidad de amar. Clínica e Investigación Relacional, 12 (1): 186-194. [ISSN 1988-2939] [Recuperado de www.ceir.info ] DOI: 10.21110/19882939.2018.120116
} 
Una difusión tan amplia se debe a que estos mitos presentan una imagen satisfactoria del deseo del hombre en aproximarse a la plenitud.

En Grecia, Dionisos, era el Dios bisexuado por excelencia, de ahí su plenitud.

En esta época, la búsqueda se hacía desde los orígenes, donde se suponía, se encontraba la totalidad, la completud o total integración.

Posteriormente aparecen ritos más elaborados como el Yoga tántrico, la Alquimia, o las elaboraciones místicas, donde se trata de lo paradójico de los elementos opuestos, donde se manifiesta la profunda insatisfacción del hombre ante su propia realidad, me refiero a la condición humana, donde se siente desgarrado y separado.

Ante esta situación el ser humano puede quedarse en lo concreto o buscar más allá, más lejos.

Actualmente asistimos a la decadencia del mito y a la pérdida del Eros, quedando el mito vacío de su sentido.

"Cuando el espíritu ya no es capaz de percibir el significado metafísico del símbolo, éste se entiende a niveles cada vez más groseros. No es la plenitud por la fusión de ambos sexos, es una superabundancia de posibilidades eróticas", dice Mircea Elíade.

Actualmente nos encontramos con una realidad más patológica: la negación de las diferencias.

Ya no hay nada que unir, se supone, pues todos somos iguales, defendiendo una vuelta al ideal narcisista del andrógino.

La negación de las diferencias tiene como consecuencia la satisfacción de la fantasía o delirio de ser omnipotente.

Estas corrientes se materializan, como ejemplo, en todo tipo de terapias que prometen curaciones garantizadas científicamente, tal como la eterna felicidad, el querer es poder, la curación sin esfuerzo, la vida eterna por la vía de la reencarnación, donde pasado, presente y futuro se alternan eternamente.

Igualmente la tecnología promete solucionar todos los problemas humanos en un futuro, en la idea de lograr un hombre y una sociedad completamente nueva y diferente, actuando como una nueva religión.

La materialización de la técnica es su Dios, que nos promete una felicidad garantizada, no siendo necesario el amor por el Otro, ya que la Ciencia nos ofrecerá la solución a todo malestar. 
Los medios habituales de difusión nos lo recuerdan constantemente. Internet nos ofrece vídeos de supuestos científicos que ofrecen todo tipo de curaciones a cualquier enfermedad, así como grupos sectarios que les siguen y todo tipo de certezas, tal como ocurre con las religiones monoteístas.

Se preguntarán Vds adónde quiero llegar con esta larga introducción, la respuesta que puedo dar se refiere al planteamiento sobre este panorama que nos descubre estar más cerca de la histeria de lo que podríamos imaginar.

Sabemos que Freud en sus Estudios sobre la histeria tuvo una intuición que nos abrió una importante vía de conocimiento sobre el ser humano.

Por mi parte, y no soy el único, considero la hipótesis de que los llamados Casos Límites no son diferentes de la patología histérica, si no que suponen una transformación y evolución de la misma.

Si la histeria necesita un falo simbólico para llenar la insoportable experiencia del vacío o carencia de no ser omnipotente, el caso límite recurre a la acción, al hacer concreto y físico, para contrarrestar la ansiedad consecuencia de su vacío ontológico, de su No - Ser.

La ausencia de la configuración de un Sí-mismo, por la ausencia de una figura maternante resulta existencialmente insoportable.

En el Congreso de la Federación Europea de Psicoanálisis, en Ginebra 1997, Andreé Green planteó la hipótesis de que "la histeria no representaría, actualmente, más que una fracción de un campo clínico: el de los casos límite".

Un poco más adelante nos habla sobre la problemática de si la angustia de separación se da en los dos casos. Especificando que la intrusión suele ser mayor en los casos límites por la menor diferenciación del Yo.

No vamos a continuar teorizando sobre esta cuestión ya que no es el motivo de esta comunicación, pero ya que mencionamos el menor desarrollo del Yo en los casos límite.... ausencias, vacío, etc en el desarrollo del Sí-mismo, nos preguntamos cómo va a ser posible el desarrollo del individuo desde su origen si sale a la vida en el seno de una sociedad narcisista que niega la diferencia masculino-femenino, donde lo generativo está idealizado y lo receptivo completamente despreciado, tanto para los hombres como para las mujeres.

La consecuencia, de todos conocida, la encontramos en la fobia a tener necesidades afectivas. 
Esta situación se denomina, despectivamente, con el término "dependencia", (¡Yo no dependo!), en el mismo sentido que en la Edad Media se mencionaba la enfermedad de la lepra, donde se consideraba a los individuos que la padecían seres merecedores de todo desprecio, como si fuera la manifestación de un castigo divino. Esta persona no merecía, por lo tanto, respeto alguno ni derechos ciudadanos.

El símbolo del andrógino, heredero del origen mítico primigenio, que como he dcho anteriormente ocupó un lugar importante en una época posterior, ha vuelto a hacerse presente en nuestra sociedad, que desde hace más de 30 años se convirtió en una sociedad narcisista o más exactamente fálico-narcisista.

"El hombre actual permanece igual a sí mismo y busca en el Otro tan solo la propia confirmación de sí mismo", dice el filósofo Surcoreano Byung-Chul Han.

Ante este panorama nos encontramos ante la dificultad para entender al Otro, al distinto, ya sea por sexo, raza, color, nivel económico o social, también por la estética ya que está investida de idealización erotizada.

Siguiendo el orden de mi exposición entraríamos en el tercer y último punto mucho más extenso que los anteriores.

Voy a hablar sobre la hipótesis, que a mi juicio, podemos desarrollar en el ámbito de nuestro trabajo clínico con los pacientes.

Partiendo del ocaso de la imago Padre - Amo, propongo pensar la refundación de la función del padre.

Hemos perdido al padre, lo hemos matado, nos hemos quedado huérfanos.

Ningún Dios-padre nos puede salvar; la nostalgia de un padre-héroe, sabemos que no se cumple, nos recuerda Massimo Recalcati.

Pero lo que el Padre nos puede ofrecer es la verdad de la que ha sido testigo, la verdad de su experiencia.

Cuando el padre utiliza la palabra para ocultar la realidad vivida, así como sus errores, se producirán los mecanismos de proyección: el padre proyectará en el hijo sus deseos y sus temores, con la correspondiente paranoia, y sus fantasías de omnipotencia.

Por este motivo J. Lacan habla de la Ley de la Palabra, la cual transmitirá "la confianza en el porvenir, el sentido de horizonte y una responsabilidad que no reivindica propiedad alguna. Cada sociedad está comprometida en conquistar su propio porvenir". 
Recalcati subraya que éste es el sentido de la verdadera herencia: el conocimiento que nos han dejado nuestros antepasados.

El padre necesario en la actualidad solo puede ser un padre humanizado, vulnerable, reconocedor de su ignorancia sobre el sentido de la vida, aunque "sí capaz de mostrar, a través de testimonios de su propia vida, que la vida puede tener sentido".

"No somos hijos de Ulises, nuestra herencia no es un reino, no somos príncipes a la espera de un padre Rey".

Somos hijos ante una vida por realizar.

Cada individuo ha nacido siendo único, dotado de unas potencias, pero desnudo ante la incertidumbre de la vida.

Nadie puede evitarnos esta realidad.

Por tanto, no es posible serlo todo, omnipotente, hombre y mujer a la vez, tampoco inmortal.

Edipo se creyó más listo que la Esfinge, creyó haberla derrotado, en realidad no aceptó ser hijo, ni ignorante, como Narciso.

Ninguno de los dos, consiguieron ser libres de la aspiración al Yo Ideal.

Lacan nos habla del efecto mortífero del espejismo de una libertad reducida a pura voluntad de goce, ya que solamente es posible la Ley del Deseo.

Cuando lo que predomina es el culto al placer,... cuando, además, supone una obligación... entonces, nos encontramos con dos resultados: el conflicto con la Ley, que no es aceptada y, lo que todavía es peor, el rechazo a la necesidad del amor.

Todo este nudo aparece desarrollado en la obra de Recalcati. Su actualidad es plena.

Otro ejemplo lo encontramos en la sustitución del sexo por el amor, no complementándolo, ya no es propiedad de Sade.

Actualmente, cualquiera puede ser Sade.

La pornografía es un ejercicio de sexo compulsivo, sin libertad, sin ley.

Vivimos en una época de decadencia por la pérdida del valor de lo simbólico, así como de la creencia en la omnipotencia.

Consecuencia de ello es la presunción de conocer al Otro. 
Se ha olvidado que lo simbólico nos da una estructura comprensiva concretada en los arquetipos, como nos enseña $C$. G. Jung nos permite conocer el sentido de lo que ocurre, y como consecuencia, el desarrollo de la función de la conciencia.

"Es mucho más trasgresivo -y por lo tanto liberador- la experiencia de fidelidad a uno mismo que el culto aleatorio a lo nuevo, dice Recalcati.

Ante este panorama pretendo ofrecer una hipótesis que sirva para intentar trabajar en mejorar los problemas de la patología más frecuente, me refiero a la posibilidad de recuperar el sentido de la Ley, Ley de leyes, la Ley no escrita.

Me refiero a la Ley de la palabra, Lacan dice que la palabra humaniza la vida a la vez que hace posible la potencia del deseo introduciendo el sentimiento del temor a la pérdida del amor, tal como nosotros lo observamos en aquellos pacientes, tan frecuentes, que tienen síndrome de Abandono.

Al mencionar la importancia de la función de la palabra estamos, implícitamente incluyendo la función del vínculo afectivo.

La vida puramente biológica deja de serlo por la acción del lenguaje, de la palabra que transmite el sentido.

No podemos sustraernos a las leyes del lenguaje, del apego, y del amor.

Pero el vínculo implica una paradoja: lo que nos hace humanos -dice Lacan- es la separación.

El lenguaje es una estructura de separación, o como dice Byung-Chul Han refiriéndose a Sócrates, el Otro es aquel al que nunca podemos llegar a conocer.

También nos dice que "el Eros arranca al sujeto de sí mismo y lo conduce fuera, hacia ese Otro, a la atopía (no lugar) como la utopía del Eros".

El cordón umbilical ha de ser amputado, romper la simbiosis es el requisito para ser único, diferenciado.

La existencia del límite, la pérdida y la carencia supone la apertura a una vida nueva.

Como se estarán dando cuenta Vds, todo lo que acabo de mencionar se va ausentando de la estructura en la sociedad actual.

No se reconoce que la aceptación de la pérdida genera el deseo.

La prohibición simbólica del incesto, impide que "todos puedan quererlo todo", de serlo todo, a saberlo todo.

Actualmente se exige todo, todo se exige, todo nos ha de ser dado. 
Cuando el hombre renuncia a la fantasía del Poder, es cuando gana sentido humano.

Lucrecio en De Rerum Natura nos habla sobre esta cuestión, sobre lo que es ser humano.

Antonio Machado dice "nada de lo humano me es ajeno", y Nietzsche se reconoce "humano, demasiado humano".

Para que la vida de una persona tenga sentido verdaderamente humano necesita ser algo para el deseo del Otro.

El caso límite no se siente deseado, querido por el Otro, porque no lo fue desde su concepción, si no que se espera que sea Otro. ¿Otro para ser querido, cómo es esto posible?.

Absurdo, e imposible.

Conocemos esos casos en los que se espera el nacimiento de una niña y lo que nace es un niño, o a la inversa, y entonces no se le reconoce.

En otros casos se espera un par de gemelos, pero nace un solo bebé.

Como aquel caso de una madre que describe que su hijo fue para ella un bulto, una cosa, a quien no pudo atender durante los primeros 5 años de su vida por estar muy ocupada.

Esta nueva criatura se encuentra sumergida en la llamada "Falta básica" sin poder, por lo tanto, desarrollar un sí mismo adecuado.

¿Qué necesita el hijo además del vínculo de empatía con la madre?. Lo que necesita es un verdadero padre, aquel que no ostenta la última palabra acerca del sentido de la vida y de la muerte.

Un ejemplo de lo que quiero decir lo encontramos en la escena Bíblica del Sacrificio de Isaac, hijo de Abraham, por orden de Yahvé, tal como nos lo recordó Freud.

Éste hijo, el más querido debe perderse, como reconocimiento de que este hijo no es propiedad de su padre.

El padre no es la Ley sino que responde a una Ley, nos dice Lacan.

Ley que impone a todos los padres perder a sus hijos, dejarlos ir, no retenerlos.

Los hijos no son una propiedad de los padres, escribe el poeta libanés Gibran Khalil.

La renuncia a ser Ley libera a la persona de la fría armadura del comportamiento normativo.

El mayor gesto de amor es abandonar la armadura, tal como podemos leer en el delicioso libro titulado El caballero de la armadura oxidada. 
Por esto Lacan, dice que el amor es dar al Otro "lo que no se tiene", es decir, "mostrar nuestra carencia".

¿Qué es lo que está pasando, cuál es la enfermedad predominante en nuestra sociedad, por qué hay tantas personas con la patología que llamamos casos límite?.

Sobre esta cuestión he dado algunas Conferencias con el título de En la Sociedad Narcisista. Lacan habla del culto al Yo, como la mayor locura... ¿por qué la llamamos locura?, pues por ser una libertado hipomaníaca, ya que está desprovista de la responsabilidad, la fuerza centrífuga no encuentra contención en la fuerza centrípeta, no existe elemento de contención, se produce la negación del origen (Adanismo es el término en español)... Todo empieza en el "aquí y ahora" que defienden muchos libros de autoayuda, negación del pasado, negación del conocimiento que ese pasado nos aporta y, por lo tanto, negación de la deuda simbólica en relación con el Otro. Recalcati traduce a Lacan diciendo: el fantasma de la libertad rechaza, junto con la experiencia del límite, la experiencia misma de filiación, de que todos somos "hijos de" antes de ser adultos.

Nuestra época rechaza toda subordinación proclamando, de manera delirante, el "hacerse a sí mismo" del hombre. Yo soy dueño de mí mismo, no me debo a nada ni a nadie, todo parte de mí y acaba en mí mismo.

El hombre actual está disociado ya que vive en un estado de libertad sin responsabilidad.

El padre deja de ser un educador, convertido en padre-hijo, renuncia a sus funciones por ser demasiado parecido a sus hijos.

El resultado lo observamos en los síntomas de padres angustiados, hijos desorientados, familias desorganizadas, dificultad para respetar las Instituciones, derrumbe de la moral pública, pérdida del discurso educativo, decadencia del sentido compartido de la vida, incapacidad de crear lazos sociales creativos, en resumen, supone el triunfo de un goce destructivo por estar desconectado del deseo.

Paradójicamente la ley escrita por cada país es reclamada constantemente como un árbitro que solucione el defecto de transmisión de su sentido simbólico.

La clínica psicoanalítica define la tendencia a invocar continuamente la Ley del código escrito como sustituto de la falta de ley internalizada en el sujeto produciendo una pleitomanía. Se trata de un uso real y persecutorio de la ley que en realidad intenta llenar el vacío dejado por la forclusión (exclusión del significado) de la ley simbólica de la palabra.

Actualmente observamos en España, pero también en otros países, la contínua utilización de la figura del Juez para resolver todo tipo de problemas, esto supone una profunda 
alteración del sentido simbólico de la función parental, que tienen cada vez más dificultad para transmitir a los hijos el sentido simbólico de los valores humanos, apelan a la ley dictada por el Juez para que les sustituya en la función de autoridad ante los hijos.

Devolver el valor simbólico supone no confundir el valor simbólico de la Ley, con la materialidad de los códigos.

Esto supone para los padres renunciar a las expectativas de sus hijos, de renuncia real a la fantasía de poder sobre los hijos, renuncia de los padres a ponerse como ejemplo y modelo a seguir, si no, por el contrario aceptar las consecuencias de sus actos así como reconocer ser dependientes de una ley universal que está por encima de todas las personas.

Muchas gracias por haberme escuchado. 